
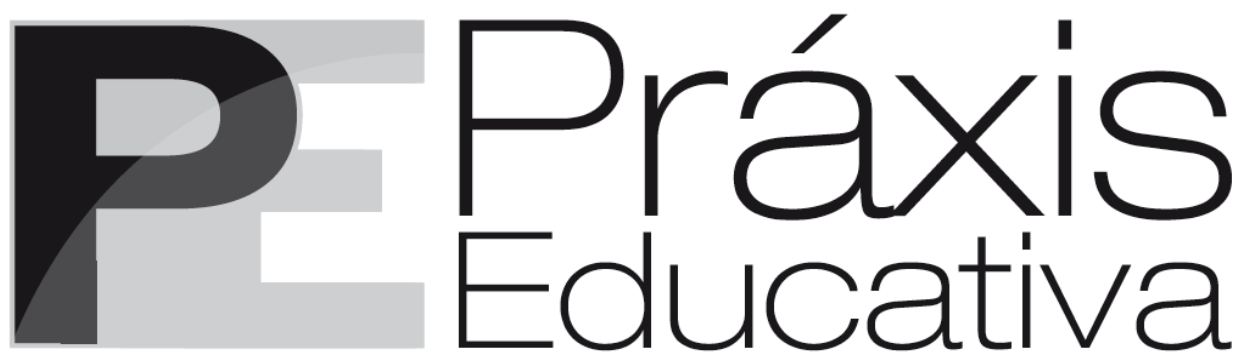

ISSN 1809-4031

elSSN 1809-4309

https://dx.doi.org/10.5212/PraxEduc.v.15.14653.022

\title{
Reforma do Ensino Médio no Estado do Rio Grande do Sul (Brasil): alinhamentos e resistências
}

\section{High school reform in the state of Rio Grande do Sul (Brazil): alignments and resistances}

\section{Reforma de la Educación Secundaria en el Estado de Rio Grande do Sul (Brasil): alineamientos y resistências}

\author{
Angela Both Chagas* \\ (iD) https://orcid.org/0000-0002-6408-7331 \\ Maria Beatriz Luce ${ }^{* *}$ \\ https://orcid.org/0000-0003-1842-164X
}

Resumo: Neste artigo, apresentamos uma análise da implementação inicial da reforma do Ensino Médio (Lei N ${ }^{\circ}$ 13.415/2017) na rede estadual do Rio Grande do Sul, de setembro de 2016 a dezembro de 2018. A partir do conceito de campo de Pierre Bourdieu (2004, 2011), buscamos compreender estratégias e posições de dois agentes no campo educacional: a Secretaria Estadual da Educação e o Conselho Estadual de Educação. Por meio de análise documental, percebemos alinhamento da Secretaria às orientações do Ministério da Educação, com reprodução da concepção de educação vinculada aos interesses hegemônicos no campo econômico. Do Conselho, observamos resistência, em primeiro lugar, pela rejeição da Medida Provisória $\mathrm{N}^{\circ} 746 / 2016$, e, após a sanção da Lei, por resistência dentro da norma, utilizando-se do jogo dentro do campo para minimizar os impactos aos estudantes.

Palavras-chave: Reforma do Ensino Médio. Lei No 13.415/2017. Rio Grande do Sul.

Abstract: In this article, we present an analysis of the first steps on the implementation of the Brazilian High School reform (Law no. 13.415/2017) in the state of Rio Grande do Sul, between September 2016 and December 2018. Based on Pierre Bourdieu's concept of field, we examined strategies and positions of two agents in the educational field: the State Department of Education and the State Council on Education. Through a document analysis we found the state Department aligned to the Ministry of Education

\footnotetext{
* Doutoranda no Programa de Pós-Graduação em Educação da Universidade Federal do Rio Grande do Sul (UFRGS). E-mail: <angela.bchagas@gmail.com>.

** Professora Titular de Política e Administração da Educação e docente do Programa de Pós-Graduação em Educação da Universidade Federal do Rio Grande do Sul (UFRGS); também docente no Programa de Pós-Graduação em Educação da Universidade Federal do Pampa (Unipampa). Doutora em Educação pela Michigan State University, EUA. E-mail: <lucemb@ufrgs.br>.
} 
guidelines, reproducing education concepts bound to hegemonic interests in the economic field. Whereas the state Council pursued a resistance strategy, initially rejecting the content of Provisional Measure no. $746 / 2016$, but after it became law, by resisting within the norm, playing the game within the field to minimize its impacts on students.

Keywords: High School reform. Law no. 13.415/2017. Rio Grande do Sul.

Resumen: En este artículo, presentamos un análisis de la implementación inicial de la reforma de la Educación Secundaria (Ley No 13.415/2017) en la red estatal de Rio Grande do Sul, de septiembre de 2016 a diciembre de 2018. A partir del concepto de campo de Pierre Bourdieu (2004, 2011), buscamos comprender estrategias y posiciones de dos agentes en el campo educativo: la Secretaría de Educación y el Consejo Estatal de Educación. Por medio de análisis documental notamos alineamiento entre la Secretaría y las directrices del Ministerio de Educación, con reproducción de la concepción de educación vinculada a los intereses hegemónicos en el campo económico. Del Consejo, observamos resistencia, en primer lugar, por el rechazo de la Medida Provisoria No 746/2016 y, después de la sanción de la Ley, por resistencia dentro de la norma, haciendo el juego dentro del campo para minimizar los impactos a los estudiantes.

Palabras clave: Reforma de la Educación Secundaria. Ley No 13.415/2017. Rio Grande do Sul.

\section{Introdução}

Diante de um grupo de estudantes que representavam as mais de 120 escolas da Rede Estadual do Rio Grande do Sul ocupadas naquele ano de 2016, o então secretário da Educação prometeu que nenhuma mudança no Ensino Médio seria feita sem a participação da sociedade, principalmente dos alunos. A declaração de Luís Antônio Alcoba de Freitas (SEDUC, 2017a) aos jovens secundaristas respondia às demandas por melhores condições de infraestrutura e de autonomia para a gestão escolar. O ponto central da pauta foi a Medida Provisória (MP $n^{\circ}$ 746/2016), recentemente apresentada pelo Governo Federal para reestruturar a última etapa da Educação Básica. A forma autoritária como a reforma do Ensino Médio foi proposta pelo governo de Michel Temer motivou protestos estudantis pelo país e críticas de educadores.

As alterações foram apresentadas em setembro de 2016 sob a forma de uma MP, medida de excepcional urgência, ignorando o "[...] movimento histórico de ampla discussão na sociedade civil e entre esta e o governo" (KUENZER, 2017, p. 334). No Rio Grande do Sul, o secretário da Educação acenou com o diálogo, por isso a pergunta: Como, de fato, ocorreram as primeiras etapas da reforma do Ensino Médio na Rede Estadual? Os principais envolvidos com as mudanças professores, estudantes e comunidade escolar - foram ouvidos ou prevaleceu a agenda autoritária do Governo Federal?

Com esses questionamentos, decidimos analisar a condução do processo de reforma na Rede Estadual do Rio Grande do Sul, responsável por 85\% das matrículas no Ensino Médio, segundo dados da Sinopse Estatística da Educação Básica 2018 (INEP, 2019). Neste artigo, enfocamos os movimentos de dois agentes relevantes no contexto: a Secretaria Estadual da Educação (Seduc) e o Conselho Estadual de Educação (CEED), responsáveis pela implementação e normatização das alterações. O estudo é derivado de uma pesquisa de Pós-Graduação, mais ampla ${ }^{2}$, cujo objetivo central foi investigar as discussões e as regulamentações decorrentes da reforma no Rio Grande do Sul, os pontos de embate no campo educacional e os possíveis gargalos para colocá-la em prática nas escolas.

\footnotetext{
${ }^{1}$ O presente trabalho foi realizado com apoio da Coordenação de Aperfeiçoamento de Pessoal de Nível Superior Brasil (Capes) - Código de Financiamento 001.

$2 \mathrm{O}$ artigo é decorrente de pesquisa de Mestrado (CHAGAS, 2019).
}

Práxis Educativa, Ponta Grossa, v. 15, e2014653, p. 1-21, 2020 
O referencial teórico-metodológico toma o conceito de campo de Pierre Bourdieu (2011, p. 206), entendido como um "[...] jogo no qual o que está em disputa é a imposição legítima dos princípios de visão e divisão do mundo social". Segundo o pensador francês, somente temos condições de compreender o que diz ou faz um agente dentro do campo se "[...] estamos em condição de nos referirmos à posição que ele ocupa nesse campo, se sabemos 'de onde ele fala"' (BOURDIEU, 2004, p. 23-24). A partir da premissa de que o campo é resultado de relações de poder, de estratégias, de interesses e de projetos em disputa, focamos no campo educacional e na sua relação com outros campos nele imbricados, como o político e o econômico.

Foram utilizadas como fontes de pesquisa as notícias veiculadas nos sites da Seduc e do CEED relacionadas ao Ensino Médio, de 22 de setembro de 2016 - quando foi apresentada a MP No 746 - até 31 de dezembro de 2018 - ao término dos períodos do Governos Federal e Estadual - e os documentos referentes às discussões e às regulamentações da reforma pelos dois agentes no mesmo período. Entre os documentos coletados, estão diagnósticos e avaliações da situação do Ensino Médio, atas de reuniões, relatórios e propostas de implementação. A análise documental evidencia as disputas dentro do campo educacional, a influência dos campos econômico e político, além dos instrumentos de conservação e de subversão dentro do processo de implementação das mudanças no âmbito da Rede Estadual do Rio Grande do Sul.

\section{A reforma do Ensino Médio}

Uma nítida inflexão na política de educação mostrou-se central na agenda do presidente Michel Temer, que apresentou a MP $\mathrm{N}^{\mathrm{o}} 746$ menos de um mês após assumir oficialmente o comando do país. A justificativa do Governo para a reestruturação do Ensino Médio foi de que era preciso tornar o currículo mais atraente aos jovens e mais alinhado às vocações de cada um. No entanto, as mudanças foram recebidas com críticas por setores historicamente ligados à educação. Em primeiro lugar, a contestação deu-se pelo fato de ter sido apresentada sob a forma de uma MP, sem diálogo com estudantes e educadores. Ferretti (2018) lembra que a origem autoritária da reforma provocou ocupações de inúmeras escolas públicas no país por parte de estudantes, descontentes com a forma e o conteúdo da política. É preciso destacar que tramitava no Congresso Nacional, desde 2013, o Projeto de Lei No 6.840/2013 com propostas de alterações no Ensino Médio.

Ferretti (2018) aponta que o Projeto de Lei No 6.840/2013, que já trazia o pilar de flexibilização curricular, era resultado da atuação de setores identificados com o empresariado que, "[...] há tempos, inclusive nos governos do PT, vêm exercendo forte influência sobre o MEC, no sentido de adequar a educação brasileira a seus interesses, entre eles os de natureza financeira" (FERRETTI, 2018, p. 32). Acácia Kuenzer (2017) afirma que as discussões em torno do PL N ${ }^{o}$ 6.840/2013 deixavam evidentes dois projetos em disputa para o Ensino Médio no Brasil: um deles alinhado a setores do empresariado e com apoio do Conselho Nacional dos Secretários de Educação (Consed), que defendem a flexibilização curricular e criticam o excessivo número de componentes curriculares presentes nas Diretrizes Curriculares Nacionais para o Ensino Médio (DCNEM) de 2012. Por outro lado, estavam as entidades e os intelectuais que buscam um projeto de educação de qualidade também para a classe trabalhadora, com um currículo que integre as dimensões da ciência, da cultura, da tecnologia e do trabalho, atribuindo significado ao conhecimento escolar.

Kuenzer (2017) aponta que essa controvérsia entre os dois modelos de educação foi sufocada do debate com a edição da MP que incorpora os interesses do setor privado e do Consed, presentes no PL No 6.840/2013. Isso evidencia a força desses agentes no campo educacional e o alinhamento dos campos econômico e político. Em fevereiro de 2017, o Congresso Nacional 
aprovou as mudanças da Medida Provisória, sancionadas em seguida pelo presidente da República. Ao analisarem as audiências públicas no Legislativo para discussão da MP e o teor da nova Lei, Ferretti e Silva (2017) são taxativos ao reconhecerem a afinação com as propostas do setor privado:

A constatação de que as mudanças propostas nessas audiências foram advindas de pessoas ou entidades com maior aderência ao governo de Michel Temer, que possuem vínculos com outros órgãos de governo ou com o setor privado, evidenciaram uma correlação de forças que privilegiou o atendimento dos interesses desse grupo em detrimento dos demais. (FERRETTI; SILVA, 2017, p. 396).

Nesse sentido, é interessante levar em conta o mapeamento feito por Peroni et al. (2018) dos principais agentes envolvidos na construção da Base Nacional Comum Curricular (BNCC) e do projeto do "novo" Ensino Médio. Segundo as autoras, são "[...] institutos e fundações ligados a grandes empresas nacionais e internacionais, bem como instituições financeiras ligadas ao mercado de capitais" (PERONI et al., 2018, p. 418) que dão o tom na construção de um projeto hegemônico de educação no Brasil. Entre os envolvidos nas reformas em curso, aparecem o Instituto Unibanco, a Fundação Lemann, o movimento Todos pela Educação, bem como o Consed e o Conselho Nacional de Educação (CNE).

Vale destacarmos aqui que a atuação desses agentes, alinhados a movimentos internacionais de reforma educacional, pode ser compreendida como um dos efeitos da globalização em relação à política educacional. Conforme afirma Verger (2019, p. 25), o fluxo internacional e o intercâmbio de ideias tiveram impacto na "[...] constituição de influentes redes transnacionais de especialistas e, acima de tudo, contribuiu para redimensionar os processos de estabelecimento de agendas e formulação de políticas educacionais em um cenário sem precedentes".

$\mathrm{Na}$ análise no teor da Lei No 13.415, de 16 de fevereiro de 2017, dividimos as mudanças em dois eixos principais: elevação da carga horária no Ensino Médio e reorganização curricular, com foco na flexibilização. Sobre o tempo de aula, a reforma determinou a ampliação progressiva de 800 horas para 1,4 mil horas anuais, com um mínimo de mil horas em um prazo máximo de cinco anos, o que representa cinco horas diárias. A determinação é ampliar para sete horas diárias, o que significa uma jornada em tempo integral. No entanto, não foram definidos prazos nem meios para que isso aconteça. No Rio Grande do Sul, apenas 12 dentre 1.177 escolas $^{3}$ foram incluídas na primeira etapa do Programa de Fomento à Implementação de Escolas de Ensino Médio em Tempo Integral, segundo consta no Decreto No 53.913 (RIO GRANDE DO SUL, 2018a). Em 2019, outras nove instituições passaram a receber a política ${ }^{4}$.

A reforma envolve ainda a flexibilização dos conteúdos. Da carga horária de todo o Ensino Médio, no máximo 1,8 mil horas (60\% do total para a jornada de cinco horas diárias) serão comuns, de acordo com a Base Nacional Comum Curricular (BNCC). O restante será divido em cinco itinerários formativos: Linguagens; Matemática; Ciências da Natureza; Ciências Humanas e Sociais Aplicadas - presentes nas diretrizes curriculares desde 2012 e na BNCC; e formação técnica e profissional. Esse é o ponto que recebeu maior destaque nas propagandas do governo. O discurso oficial exaltou a possibilidade de o estudante poder optar por uma área de seu maior interesse para aprofundar conhecimentos. No entanto, a Lei No 13.415/2017 deixa claro que as escolas não serão

\footnotetext{
${ }^{3}$ Levamos em conta o total de escolas públicas no Rio Grande do Sul em 2018, segundo a Sinopse Estatística da Educação Básica (INEP, 2019).

4 Notícia aponta a ampliação do tempo integral para mais nove escolas. Disponível em: $<$ https://educacao.rs.gov.br/estado-tera-9-novas-escolas-de-ensino-medio-em-tempo-integral $>$. Acesso em: 15 ago. 2019.
}

Práxis Educativa, Ponta Grossa, v. 15, e2014653, p. 1-21, 2020 Disponível em: < https://www.revistas2.uepg.br/index.php/praxiseducativa> 
obrigadas a oferecer os cinco itinerários, já que a oferta vai depender das condições da rede de ensino (BRASIL, 2017).

A Lei $\mathrm{N}^{0} 13.415 / 2017$ aponta ainda que a formação técnica e profissional poderá ser ofertada em parceria com instituições credenciadas, seja na modalidade presencial ou a distância, inclusive fora do ambiente escolar (BRASIL, 2017). Isso abre caminho para a utilização de recursos públicos para financiar a oferta privada da educação (SILVA, 2018). O aluno, por sua vez, poderá comprovar parte da carga horária com experiência prática de trabalho no setor produtivo - o que poderá levar a uma redução das horas de atividade escolar, com uma precarização da formação tendo em vista a rápida inserção no mercado de trabalho. A flexibilização também impacta os docentes desse itinerário formativo, que poderão ser substituídos por profissionais que comprovem "notório saber" em sua área de atuação.

A implementação ocorrerá, de acordo com a Lei № 13.415/2017, em um prazo de dois anos a partir da publicação da BNCC, o que se efetivou somente em dezembro de 2018. Assim, a reforma chegará às escolas em 2021. No entanto, um projeto-piloto está em andamento para levar a flexibilidade curricular a 3 mil escolas públicas do país já em 2020. No Rio Grande do Sul, dados coletados junto à Seduc no fim de 2018 apontavam para o envolvimento de 301 escolas. No entanto, em agosto de 2019, o número havia caído para 298 instituições ${ }^{5}$.

\section{A replicação do discurso do "novo" Ensino Médio: o que indicam os documentos da Seduc}

A fim de avaliar como se dão as discussões para a implementação da reestruturação do Ensino Médio na Rede Estadual do Rio Grande do Sul, analisamos os movimentos de dois agentes importantes na constituição do campo: a Seduc e o CEED, responsáveis pela implementação e pela normatização da nova política. Assim, o campo educacional é compreendido como um espaço de lutas para conservar ou transformar esse campo (BOURDIEU, 2004), e é a posição dos agentes dentro desse campo que vai determinar seus movimentos.

Para compreender a posição da Seduc e do CEED dentro do campo educacional, analisamos a sua estrutura e o perfil dos ocupantes dos postos de gestão. A origem da Secretaria remonta a 1935, com o Decreto $N^{0}$ 5.964, que criou a Secretaria de Estado dos Negócios da Educação e Saúde 6 . A configuração da pasta responsável pela educação no Estado passou por inúmeras alterações até se chegar à estrutura atual. A última realizada no período deste estudo ocorreu em abril de 2018, com o Decreto No 54.015, de 10 de abril de 2018 (RIO GRANDE DO SUL, 2018b). Entre as alterações, está a substituição do Departamento de Articulação com os Municípios pelo Departamento de Coordenação das Regionais, além do detalhamento das atribuições do órgão, o que não constava no anterior Decreto $N^{\circ} 51.906$, de 14 de outubro de 2014 (RIO GRANDE DO SUL, 2014).

É interessante observar que não havia nenhuma menção, entre as atribuições da Seduc-RS, de planejamento de políticas públicas para a Educação Básica, nem especificamente para o Ensino Médio. O único item que aborda a Educação Básica, no Decreto $N^{\circ} 54.015 / 2018$, no artigo $1^{\circ}$, faz referência apenas às atribuições de "[...] executar, promover, financiar e fiscalizar as políticas" (RIO GRANDE DO SUL, 2018b, p. 1); indica, desse modo, apenas que a Secretaria é uma executora de tarefas, estando subsumidas ou alhures às funções de planejamento e de gestão das políticas,

\footnotetext{
${ }^{5}$ Site criado pela Seduc para tratar do "novo" Ensino Médio apresenta a lista de escolas do projeto-piloto. Disponível em: <http://portal.educacao.rs.gov.br/novo-ensino-medio>. Acesso em: 21 ago. 2019.

${ }^{6}$ O Decreto pode ser conferido no repositório digital da Universidade Federal de Santa Catarina (UFSC). Disponível em: <https://repositorio.ufsc.br/handle/123456789/104899>. Acesso em: 28 ago. 2019.
}

Práxis Educativa, Ponta Grossa, v. 15, e2014653, p. 1-21, 2020 Disponível em: < https://www.revistas2.uepg.br/index.php/praxiseducativa> 
inerentes às competências federativas estaduais e também preconizadas pelo Plano Nacional de Educação e pelo Plano de Educação do Estado do Rio Grande do Sul.

A propósito, vale destacarmos que o Plano Estadual de Educação - Lei No 14.705, de 25 de junho de 2015 (RIO GRANDE DO SUL, 2015, p. 47) coloca como um dos pilares da gestão democrática a "[...] participação de todos os segmentos da comunidade no planejamento e na avaliação institucional já que são os maiores envolvidos neste processo, sob a responsabilidade dos sistemas educacionais e das unidades de ensino", o que oportuniza questionar onde, quem e de que forma são tomadas as decisões sobre uma reforma política estruturante da Educação Básica.

Durante o período de estudo - de setembro de 2016 a dezembro de 2018 -, o cargo de Secretário de Estado da Educação foi ocupado por duas pessoas. No caso do primeiro titular da pasta, no período, questões partidárias pesaram na indicação. Luís Antônio Alcoba de Freitas é formado em Direito, funcionário concursado da Advocacia-Geral da União (AGU). Adjunto na pasta, assumiu a titularidade após o então secretário Vieira da Cunha, que havia sido vereador e deputado estadual e federal pelo Partido Democrático Trabalhista (PDT) e deixar o posto com a intenção de concorrer à prefeitura de Porto Alegre.

Alcoba de Freitas assumiu o comando da Seduc em meio a uma greve de professores e a ocupação de mais de 120 escolas estaduais por estudantes secundaristas. Durante o período de ocupações, a atuação do Secretário foi marcada pelo diálogo com os alunos. Em uma cartacompromisso entregue aos estudantes como proposta de desocupação das instituições de ensino, o Governo Estadual disse que as ocupações "[...] sempre foram tratadas democraticamente no Rio Grande do Sul. Trata-se de uma pauta da Educação" (RIO GRANDE DO SUL, 2016a, n.p.). Ao deixar o cargo, após o PDT anunciar a saída do governo de José Ivo Sartori (Movimento Democrático Brasileiro, MDB), em abril de 2017, Alcoba afirmou que a sua gestão teve como principal bandeira o diálogo com professores e comunidades escolares (SEDUC, 2017a).

O substituto de Alcoba, o administrador de empresas Ronald Krummenauer, também não tinha ligação direta com a educação, mas, diferentemente do Secretário anterior, não apresenta vinculação partidária oficial, mas, sim, forte ligação com o setor empresarial. A Agenda 2020, movimento do qual Krummenauer era diretor desde a sua criação, em 2006, reúne líderes empresariais e outros segmentos da sociedade civil na mobilização em torno de propostas para o Estado, incluindo a área da educação. No Caderno de Propostas de $2018^{7}$, aparece como um dos problemas a inadequação da educação às exigências do século XXI, com práticas educativas pouco inovadoras, principalmente no Ensino Médio. Entre as sugestões está o fim da eleição de diretores de escola, como preconiza a Lei da Gestão Democrática (Lei No 10.576/1995), com a escolha de passar por "critérios técnicos de mérito". Também merecem destaque as propostas de valorização de "instituições mais eficazes em termos de processos de gestão", adequação do plano de carreira do magistério, otimização dos recursos físicos, humanos e financeiros, além de racionalização da rede, com municipalização de escolas.

Quando assumiu o cargo, Krummenauer demonstrou que levaria adiante as pautas da Agenda 2020 para a educação. No discurso de posse, afirmou que "[...] os estudantes estão saindo do Ensino Médio com menos do que o necessário para o mercado de trabalho” (SEDUC, 2017b,

7 O Caderno de Propostas da Agenda 2020 para a educação pode ser conferido em: <https://conteudo.agenda2020.com.br/caderno-de-propostas-2018>. Acesso em: 2 set. 2019. 


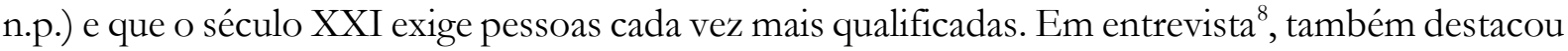
as parcerias com a iniciativa privada para investimentos nas escolas estaduais.

A análise dos perfis dos dois secretários que ocuparam o cargo durante o período da pesquisa aponta que nenhum deles tinha capital simbólico no campo educacional - um advogado público de carreira federal, outro administrador de um projeto político de lideranças empresariais. O que permeia é um alinhamento, do primeiro, ao campo político e, do segundo, ao campo econômico.

Situar quem são os atores responsáveis pela implementação da nova política para o Ensino Médio ajuda a compreender a posição desse agente institucional dentro do campo educacional. Assim, passamos a analisar as notícias e os documentos produzidos pela Seduc-RS em relação às mudanças no Ensino Médio, a partir da definição de três categorias de análise - também utilizadas nos materiais do CEED. As categorias foram construídas após a leitura de todas as notícias e dos documentos e estão referenciadas teoricamente com Pierre Bourdieu. Segundo o pensador francês (BOURDIEU, 2004), dependendo de sua posição dentro do campo, o agente vai adotar uma estratégia de conservação da estrutura ou de sua transformação (estratégia de subversão). Pela importância do MEC na elaboração das políticas educacionais, com forte capital simbólico dentro do campo, e pelo alinhamento com outros agentes, como o Consed e o CNE, entendemos que a postura dominante é de conservação do teor da Lei $N^{\circ}$ 13.415/2017 e de sua implementação na íntegra pelos Estados. Assim, as categorias de análise para apontar a posição da Seduc e do CEED dentro do campo foram definidas como:

- Alinhamento: entendido como uma estratégia do agente de conservação da estrutura, pela reprodução da política do MEC e sua implementação na íntegra na Rede Estadual do Rio Grande do Sul.

- Resistência: reflete uma estratégia de transformação da estrutura (subversão), pela postura de resistência ao teor da Lei $N^{\circ}$ 13.415/2017 e de adoção de proposições alternativas dentro do jogo no campo educacional.

- Sem posicionamento: quando não é possível definir se a notícia ou o documento refletem uma posição de alinhamento ou de resistência à Lei No 13.415/2017.

De 22 de setembro de 2016 a 31 de dezembro de 2018, foram publicadas pela Seduc 121 notícias que abordam o Ensino Médio. No entanto, detivemo-nos na análise dos 28 textos que tratam especificamente da Lei No 13.415/2017, da BNCC e da implementação do Ensino Médio de Tempo Integral, por serem políticas relacionadas às mudanças na etapa. Do total, 24 demonstram uma postura de total alinhamento ao projeto do governo Temer para o Ensino Médio. Apenas quatro foram enquadradas como sem posicionamento e nenhuma na categoria de resistência. O que chama atenção é que, tanto no período da gestão de Alcoba quanto no de Krummenauer, ocorreu uma reprodução das orientações do MEC, inclusive no teor das notícias, com replicação de conteúdos do Ministério e do Consed. Um exemplo disso é o texto de 16 de fevereiro de 2017, que informa sobre a sanção da Lei No 13.415/2017 (SEDUC, 2017c), retirado na íntegra do portal do MEC.

Há, contudo, diferença entre as declarações dos secretários. Alcoba adotava uma postura de maior neutralidade em relação à reforma, embora no geral as notícias no site tenham sido favoráveis às mudanças. Isso pode ser verificado em encontros com estudantes das escolas que foram ocupadas no Estado, conforme apontamos na abertura deste artigo: "Nenhuma modificação

\footnotetext{
8 Entrevista de Ronald Krummenauer ao jornal Zero Hora. Disponível em: <https://gauchazh.clicrbs.com.br/educacao-e-emprego/noticia/2017/05/temos-de-buscar-alternativas-sem-rancoideologico-diz-novo-secretario-estadual-da-educacao-9785427.html>. Acesso em: 2 set. 2019.
} 
no currículo do Ensino Médio será feita sem a discussão prévia com a sociedade, especialmente com os estudantes" (SEDUC, 2017d), disse o secretário em $1^{\circ}$ de novembro de 2016. Já Krummenauer demonstrou, desde que assumiu o cargo, a necessidade urgente de promover as mudanças. "O mercado de trabalho do século XXI é muito diferente do século XX. Está mais do que na hora que nós darmos um rumo diferente daquele modelo que tínhamos como referência" (SEDUC, 2018), afirmou em texto de 5 de julho de 2018.

Além das notícias, também foram analisados os documentos produzidos pela Seduc no período desta pesquisa em relação às mudanças no Ensino Médio. Foram definidos como documentos as publicações oficiais, as apresentações feitas em eventos sobre as mudanças na etapa, os diagnósticos sobre a situação da Rede Estadual, as pautas de reuniões do Grupo de Trabalho criado para debater a Lei $\mathrm{N}^{\circ} 13.415 / 2017$, entre outros. Os materiais que não configuram como publicações oficiais, mas que fazem parte do processo de discussão interna, foram repassados pela assessoria técnica da Secretaria para compor o escopo do estudo após solicitação formalizada pelas pesquisadoras ${ }^{9}$.

Dos 19 materiais selecionados, 10 foram incluídos na categoria de alinhamento, por reproduzirem uma posição da Seduc em sintonia com o que preconizam as propostas do MEC dentro do campo educacional. Outros seis foram classificados como sem posicionamento, por não haver um detalhamento em relação a uma tomada de posição. Nenhum foi enquadrado como resistência. Outros três documentos foram mantidos na pesquisa, mas sem categorização porque foram produzidos pelo Ministério, não pela Seduc. No entanto, são importantes elementos para a compreensão das ações da Secretaria.

O primeiro documento incluído na categoria de alinhamento refere-se ao Decreto $\mathrm{N}^{\circ}$ 53.913, de 7 de fevereiro de 2018, que instituiu o Programa de Educação em Tempo Integral no Ensino Médio, nas escolas da Rede Estadual (RIO GRANDE DO SUL, 2018a). O Decreto é de suma importância na análise porque compreende a primeira ação em relação à implementação do novo modelo de Ensino Médio presente na Lei $N^{o}$ 13.415/2017, que instituiu o Programa de Fomento ao Ensino Médio de Tempo Integral (EMTI). É possível observar no texto um claro alinhamento da Seduc à proposta do Governo Federal, na medida em que são seguidas à risca todas as orientações presentes no programa de fomento ao EMTI. Isso também fica evidente quando, entre as finalidades do programa, aparece, no Art. $2^{\circ}$ do Decreto $\mathrm{N}^{\circ}$ 53.913/2018, a de “[...] promover ações compartilhadas com o Ministério da Educação - MEC - para a melhoria do ensino médio" (RIO GRANDE DO SUL, 2018a, p. 2). Também vale destacar, no mesmo artigo, o objetivo de "[...] consolidar o modelo de gestão para resultados nas escolas estaduais de educação em tempo integral em todo o Estado" (RIO GRANDE DO SUL, 2018a, p. 2). A proposta está alinhada ao que aparece na Portaria No 1.145/2016, do MEC (BRASIL, 2016), que coloca entre as atribuições das secretarias estaduais monitorar e avaliar o desempenho das escolas, com metas para redução das taxas de reprovação e abandono e de melhoria nas avaliações de desempenho.

Outro documento da categoria de alinhamento que merece destaque é uma apresentação feita pelo secretário Ronald Krummenauer no $2^{\circ}$ Seminário Estadual sobre o Ensino Médio, realizado no dia 12 de setembro de 2017 . No segundo slide, aparece a imagem de uma orquestra e ao lado está escrito: "O Novo Ensino Médio sendo edificado por múltiplas vozes. Portanto uma construção polifônica!”. O indicativo da mensagem é de que as mudanças na etapa são uma construção coletiva, uma posição no campo educacional bem diferente daquela feita por acadêmicos, que criticam a falta de debate e a apresentação das mudanças via Medida Provisória. O que mais chama atenção vem adiante: pelo menos dois slides são reproduções da apresentação feita pelo então Secretário de Educação Básica do MEC, Rossieli Soares da Silva (que depois se

\footnotetext{
${ }^{9}$ A íntegra dos documentos está disponível nos anexos da dissertação de Mestrado de Chagas (2019).
} 
tornou Ministro da Educação), no $1^{\circ}$ Seminário sobre o Ensino Médio, realizado em abril, conforme apresentamos nas figuras a seguir ${ }^{10}$.

A Figura 1 mostra uma composição da apresentação feita por Rossieli em abril de 2017, quando tratou dos problemas de formação dos professores que lecionam na Educação Básica. O mesmo gráfico foi utilizado por Ronald Krummenauer.

Figura 1 - Apresentação do representante do MEC x Apresentação do secretário Ronald Krummenauer

\section{PROFESSORES DA EDUCAÇÃO BÁSICA - BRASIL - 2015}

\section{TOTAL: 2.187 .154}

$614.834 \mathrm{mil}$ professores ainda não tem licenciatura nem complementação

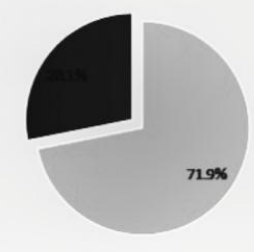

PROFESSORES DA EDUCAÇÃO BÁSICA - BRASIL - 2015

TOTAL: 2.187.154

\subsection{4 mil}

professores ainda não tem licenciatura nem complementação pedagógica

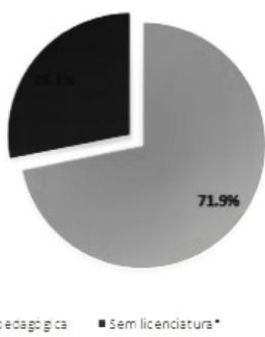

Fonte: Seduc (2017 apud CHAGAS, 2019, p. 89).

Já a Figura 2 compreende uma lista de dados detalhados pelo então Secretário de Educação Básica do MEC sobre a "falência do atual Ensino Médio no Brasil", utilizada para justificar a "relevância e urgência das mudanças". Os mesmos argumentos apresentados por Rossieli, em abril de 2017, foram utilizados pelo dirigente da Seduc cinco meses depois para defender o "novo" Ensino Médio. Além de um alinhamento, esses materiais indicam uma posição de reprodução integral das estratégias e das orientações do MEC dentro do campo educacional.

\footnotetext{
${ }^{10}$ A apresentação do Secretário do MEC durante o seminário no RS foi encaminhada pela assessoria técnica da Seduc para esta pesquisa. Não recebemos apresentação referente à fala de Luiz Antônio Alcoba de Freitas, titular da Seduc à época, porque ele não utilizou este recurso, segundo a assessoria.
} 
Figura 2 - Apresentação do representante do MEC x Apresentação do secretário Ronald Krummenauer

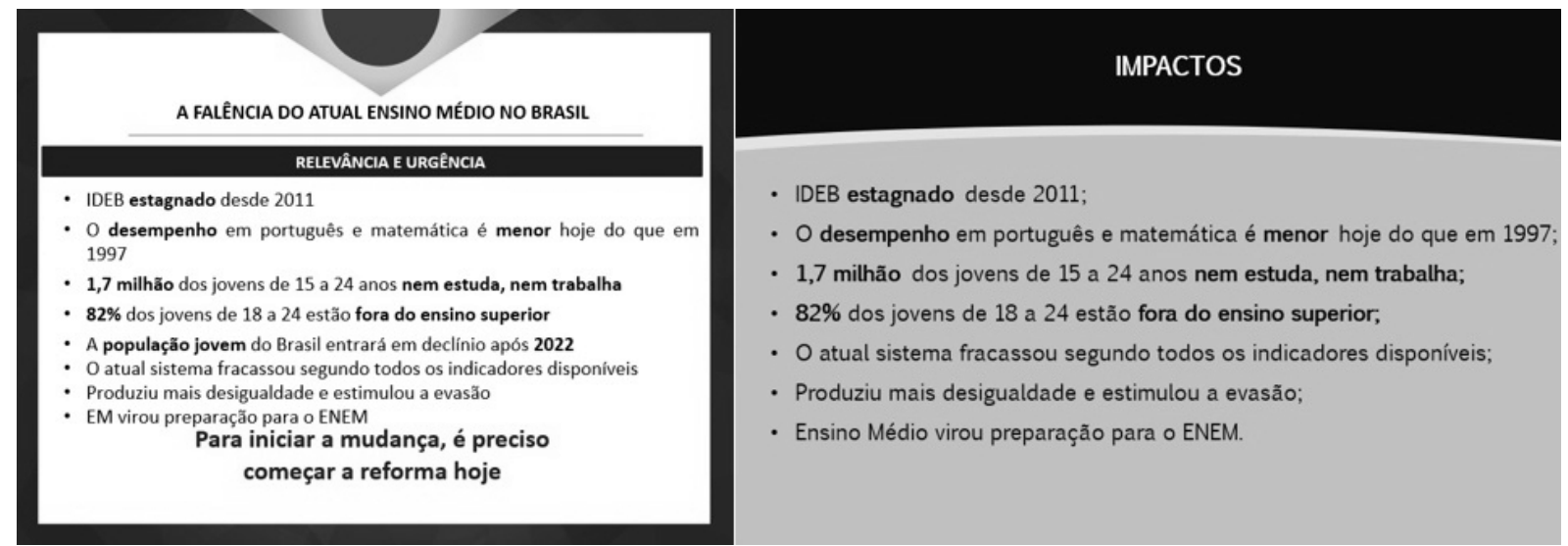

Fonte: Seduc (2017 apud CHAGAS, 2019, p. 90).

Ainda sobre a apresentação de Krummenauer, outro slide lista uma série de ações, que vão desde os seminários realizados pela Seduc, passando pela instalação do Grupo de Trabalho interno, até a participação em um Grupo de Trabalho (GT) criado pelo Consed e um curso do Insper, do qual participaram técnicos da Seduc, conforme abordaremos a seguir.

Figura 3 - Apresentação do secretário Krummenauer sobre as ações da Seduc

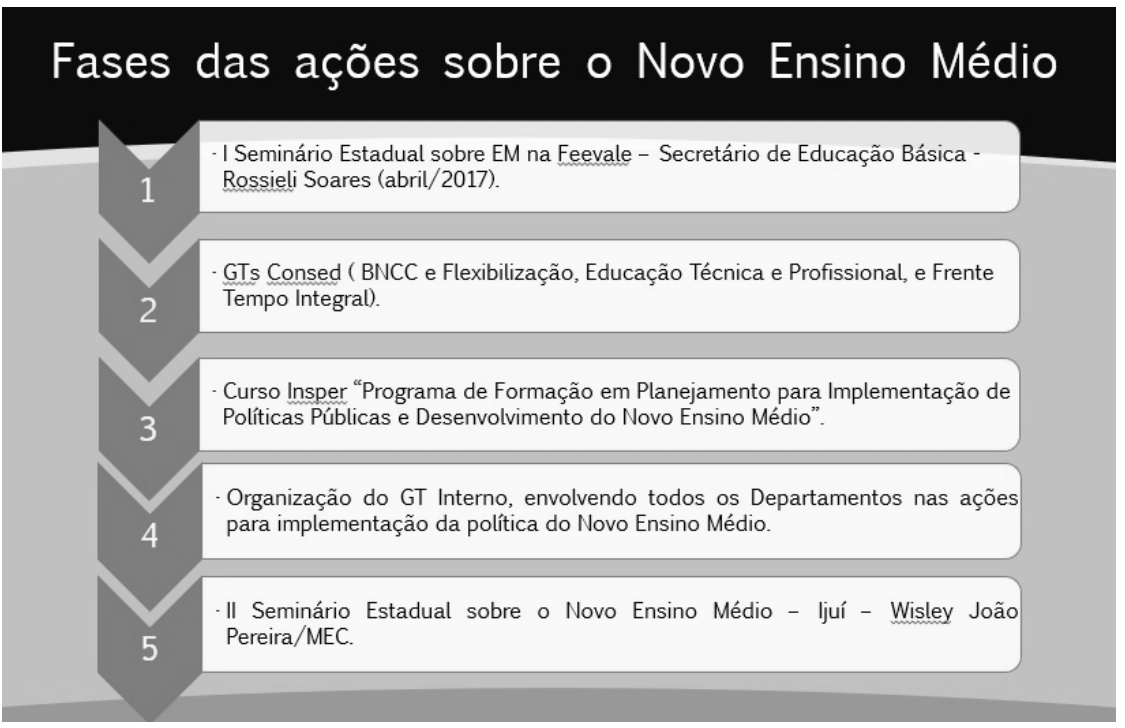

Fonte: Seduc (2017 apud CHAGAS, 2019, p. 91).

Um terceiro documento que chama atenção na categoria de alinhamento compreende a pauta e a memória da primeira reunião do Grupo de Trabalho criado pela Seduc, envolvendo todos os departamentos nas ações para implementação da nova política para o Ensino Médio. O primeiro encontro do GT foi realizado no dia 6 de setembro de 2017, com 20 profissionais de diferentes departamentos da Seduc. A memória da reunião aponta para a influência de outro agente com força no campo educacional, o Consed, por meio de um curso promovido em parceria com o Insper e fundações empresariais para capacitar os gestores e técnicos das Secretarias da Educação na implementação da reforma. A iniciativa é chamada de "Programa de Formação em Planejamento para Implementação de Políticas Públicas e Desenvolvimento do Ensino Médio". No resumo da reunião, aparece que foi combinado entre os participantes que "alguns pontos e referenciais desse curso será parte da análise desse GT que se compõe hoje”. Inclusive foi feita uma apresentação específica sobre o curso do Insper, "mostrando os módulos de estudo do mesmo". Além disso, no 
documento que detalha a primeira reunião do GT, é apontado que a análise da demanda (um mapeamento da situação da Rede Estadual de Ensino Médio) foi construída como uma tarefa desse curso.

O curso no Insper, conforme detalhamento no site do Consed ${ }^{11}$, foi desenvolvido em parceria com o Itaú BBA e com o Instituto Unibanco, fundações empresariais que têm demonstrado interesse nas mudanças no Ensino Médio, inclusive com defesa da BNCC e da flexibilidade curricular. Entre os objetivos do curso, está o de elaborar planos de implementação da Lei N ${ }^{0}$ 13.415/2017 envolvendo todas as Secretarias Estaduais de Educação. Participaram do curso, realizado em 2017 e 2018, quatro técnicos da Seduc ligados às políticas para o Ensino Médio.

Vale destacarmos, ainda, a participação da Seduc no GT criado pelo Consed para acompanhar o processo de implementação da reforma em três frentes: BNCC e flexibilização curricular; Educação Profissional e Técnica; e Ensino de Tempo Integral. Essa ação tem como "parceiros técnicos e financiadores" o Itaú BBA, o Instituto Unibanco e o Instituto Natura, conforme consta no site do Conselho ${ }^{12}$, o que reforça a atuação de agentes do campo econômico em defesa da reforma e sua influência na atuação do campo educacional, especialmente nas posições da Seduc.

Um quarto documento de destaque na categoria de alinhamento é uma apresentação feita pela equipe da Seduc a representantes das Coordenadorias Regionais de Educação durante formação realizada em Porto Alegre em novembro de 2018. No material, são elencados dados do MEC sobre a situação da etapa, inclusive com a logomarca do Ministério nos slides, e um panorama da Rede Estadual (resultados no Índice de Desenvolvimento da Educação Básica, Sistema Estadual de Avaliação, taxa de aprovação, abandono etc.). A apresentação cita como um desafio a ser enfrentado a situação dos municípios que contam com apenas uma escola de Ensino Médio, mas em nenhum momento são apresentadas propostas para resolver essa questão.

Outra apresentação feita nessa mesma formação para representantes das coordenadorias trata da seleção de escolas-piloto para atender às propostas das portarias do MEC No 649 e 1.023/2018 (BRASIL, 2018) que tratam do programa de apoio ao Novo Ensino Médio e da avaliação de impacto no EMTI. Em um dos slides (Figura 4), é detalhado o cronograma de implementação das mudanças.

Figura 4 - Cronograma de implementação das escolas-piloto

\section{Cronograma:}

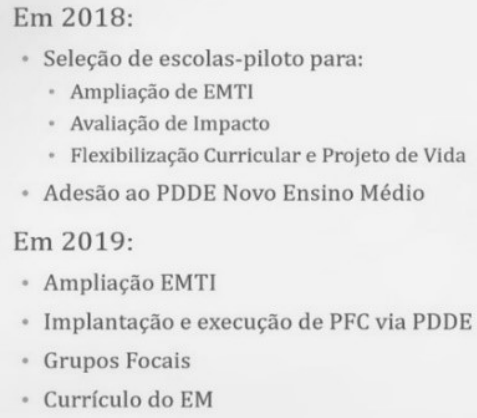

Fonte: Seduc (2018 apud CHAGAS, 2019, p. 96).

\footnotetext{
11 Detalhamento do curso realizado pelo Consed/Inper em: <http://www.consed.org.br/consed/gt-ensinomedio/curso-de-planejamento-1>. Acesso em: 4 set. 2019.

${ }^{12}$ GT do Ensino Médio no Consed disponível em: <: http://www.consed.org.br/consed/gt-ensino-medio>. Acesso em: 4 set. 2019.
} 
O cronograma está alinhado ao Programa de Apoio ao Novo Ensino Médio, definido por meio da Portaria No 649 (BRASIL, 2018), ao qual a Seduc/RS aderiu. Documento orientador da Portaria, publicado no site do novo Ensino Médio em dezembro de 2018, aponta que o Programa foi construído em "diálogo com o Consed", com o objetivo de subsidiar as 27 unidades da Federação na elaboração e na execução de um "Plano de Implementação do Novo Ensino Médio". Dentre as ações estão:

- Apoio técnico para elaboração e execução do Plano de Implementação: estão incluídos no suporte do MEC à realização de diagnósticos sobre a rede; estudos para viabilizar a reestruturação curricular; formação continuada para professores, gestores e técnicos, principalmente com foco na construção dos itinerários formativos; articulação com parceiros locais, especialmente para definição da oferta do itinerário da formação técnica e profissional; e mobilização da comunidade escolar.

- Implantação de escolas-piloto: as instituições selecionadas deverão ofertar, no mínimo, dois itinerários formativos a partir de 2020. Para isso, foi definido o repasse de recursos via Programa Dinheiro Direto na Escola (PDDE).

- Avaliação de Impacto do EMTI: parte das escolas selecionadas dentro do projeto-piloto foi designada por sorteio (cumprindo critérios de elegibilidade), para uma avaliação de impacto do tempo integral. O objetivo é comparar escolas com ou sem a política de ampliação da jornada escolar.

- Grupo focal: uma parte das escolas do projeto-piloto foi designada para passar por um acompanhamento mais intenso mediante essa técnica. Esse grupo foi definido pelas Secretarias, garantindo diferentes perfis.

A Seduc-RS aderiu ao programa-piloto e encaminhou para esta pesquisa uma lista de 301 escolas que iriam participar das ações a partir de 2019. Ao longo do ano, o número foi reduzido para 298, conforme consta no site criado pela Seduc com informações sobre o projeto-piloto ${ }^{13}$. De acordo com o cronograma apresentado pela Seduc, ficou definido para 2019 os debates para as mudanças curriculares - incluindo a Proposta de Flexibilização Curricular (PFC) nas instituições selecionadas. A implantação efetiva das escolas-piloto será em 2020, com ampliação do modelo para toda a rede até 2022 .

Além do alinhamento da Seduc às orientações do MEC, em sintonia com o Consed e fundações empresariais, percebemos, nos documentos analisados, uma ausência de planejamento que dê conta de abarcar as especificidades da Rede Estadual do Rio Grande do Sul. Um exemplo disso é o documento enquadrado na categoria sem posicionamento, que apresenta um diagnóstico da rede. Um ponto que merece atenção nesse material é a existência de uma preocupação, no âmbito da Secretaria, com a oferta diversificada nos municípios que possuem apenas uma escola estadual de Ensino Médio. Todavia, é feita apenas uma apresentação dos números, sem nenhum indicativo do que pode vir a ser adotado para garantir a flexibilidade curricular nessas instituições que são únicas a ofertar a etapa em suas localidades. Também não verificamos propostas relacionadas à melhoria das condições de infraestrutura das escolas estaduais nem um detalhamento sobre como ampliar a Educação Profissional e sobre como garantir professores com formação adequada.

Chama atenção ainda que, nessa fase inicial, não houve registro de envolvimento das comunidades escolares no debate sobre a implementação das mudanças, como prevê o Plano Estadual de Educação. A posição de Luís Antônio Alcoba de Freitas em encontro com estudantes

13 Site criado pela Seduc com informações sobre o "novo" Ensino Médio disponível em: <http://portal.educacao.rs.gov.br/novo-ensino-medio>. Acesso em: 5 set. 2019. 
ficou apenas na retórica, não encontrando eco nos movimentos da Seduc-RS durante a sua gestão e, posteriormente, quando a pasta passou para o comando de Ronald Krummenauer.

\section{CEED: da resistência à incógnita}

Previsto na Constituição Estadual de 1935, o Conselho Estadual da Educação foi criado pelo Decreto $\mathrm{N}^{\circ}$ 6.105, de 1936. Desde então, passou por diversas alterações em suas funções, estrutura e composição. A última delas foi dada pela Lei No 11.452, de 2000. Entre as funções está a de fixar normas para o funcionamento, o reconhecimento e a inspeção dos estabelecimentos de ensino, bem como autorizar o funcionamento de instituições de ensino da rede pública e privada, acompanhar a execução dos planos educacionais do Estado, emitir pareceres sobre assuntos e questões de natureza pedagógica, estabelecer medidas para expansão, consolidação e aperfeiçoamento do Sistema Estadual de Ensino, entre outras atribuições.

O Conselho é composto por 22 membros nomeados pelo governador do Estado, sendo sete de sua livre escolha e 15 designados a partir de listas tríplices apresentadas por entidades representativas da comunidade escolar. $O$ mandato é de quatro anos, sendo permitida uma recondução, e termina em 15 de abril dos anos pares, cessando, de dois em dois anos, os mandatos de 11 conselheiros, alternadamente.

Como há renovação no Conselho a cada dois anos, no período de pesquisa, o órgão teve substituição de nove conselheiros, sendo três deles indicados pelo governador José Ivo Sartori (MDB), em substituição aos membros escolhidos anteriormente pelo governador Tarso Genro (Partido dos Trabalhadores - PT). A presidência do Conselho também sofreu alteração, com a saída de Domingos Antônio Buffon, nomeado como conselheiro em 2014 pelo governo Tarso. Quem assumiu o posto foi a conselheira Sônia Maria Seadi Veríssimo da Fonseca, nomeada em vaga do Executivo pelo governo Sartori em 2016. Ainda houve alteração na composição da comissão de Ensino Médio e Educação Superior, coordenada até abril de 2018 pela professora da Faculdade de Educação da Universidade Federal do Rio Grande do Sul (UFRGS) Jaqueline Moll, que representava o Executivo Estadual, nomeada em 2014 por Tarso. Com o fim do mandato de Moll, assumiu Ruben Werner Goldmeyer, diretor-executivo da Rede Sinodal de Educação, indicado pelo governo Sartori.

A constituição do CEED e as suas relações internas, além dos interesses representados pelos seus conselheiros, são importantes para dar conta da compreensão do órgão como um agente de destaque dentro do campo educacional. Nesse sentido, a análise das notícias e dos documentos produzidos no período da pesquisa ajudam na compreensão da posição do órgão em relação à reforma do Ensino Médio.

De 22 de setembro de 2016 até 31 de dezembro de 2018, foram publicadas 17 notícias no site do CEED relacionadas ao Ensino Médio - um número bem menor em comparação aos 121 textos sobre a temática disponibilizados pela Seduc. É importante destacarmos que, desde a posse da nova presidência do Conselho, em abril de 2018, nenhum material foi disponibilizado na página do CEED sobre o Ensino Médio, o que dificulta a análise desse período.

Dos 17 textos referentes ao Ensino Médio, foram analisados 14 deles, que tratam especificamente da reforma na etapa. Desse recorte, 10 foram incluídos na categoria sem posicionamento, em função de as notícias apresentarem pouco detalhamento, configurando-se apenas como uma descrição de eventos. Nenhum texto foi enquadrado como alinhamento, e quatro foram incluídos na categoria de resistência. 
A primeira notícia de resistência publicada (CEED, 2016), seis dias após o governo Temer propor as mudanças, pede a retirada de tramitação da MP $\mathrm{N}^{\circ}$ 746/2016. A publicação considera "autoritária" a mudança via Medida Provisória e aponta alguns problemas: aligeiramento curricular para ingresso precoce no mundo do trabalho, descarte de áreas essenciais, flexibilização diante de condições defasadas das redes públicas, fragilização e desvalorização da formação de professores, sustentabilidade do financiamento e a política de parcerias com o setor privado.

Da posição inicial de rejeição total às mudanças impostas via MP, após a aprovação da Lei No 13.415/2017 no Congresso Nacional, o CEED adotou uma postura crítica, mas de diálogo sobre o que poderia ser feito diante das alterações. Assim, em abril de 2017, foi publicada notícia que detalha orientações para as redes de ensino sobre a implementação das mudanças no Ensino Médio (CEED, 2017a). O Conselho diz que as alterações somente poderão ser implementadas após a aprovação da BNCC e das normas complementares do CEED. Outra notícia, de maio de 2017, detalha o Parecer $N^{o}$ 02/2017, a fim de esclarecer dúvidas no período de transição para o novo modelo e propor a criação de um grupo de trabalho para discutir a reforma (CEED, 2017b). A quarta notícia foi publicada em 22 de março de 2018 e se refere à aprovação da Resolução No 340/2018, que define Diretrizes Operacionais para a oferta do Ensino Médio no Sistema Estadual de Ensino (CEED, 2018a). O texto destaca que ocorreram inúmeros debates com os protagonistas dos processos de ensino e aprendizagem no Estado com o objetivo de garantir um "legado pedagógico a partir da reforma" (CEED, 2018a, n.p.). O texto ainda aborda os princípios presentes nas novas diretrizes, alinhados com as Diretrizes Curriculares de 2012, e não com o modelo de competências como aparece nas novas diretrizes nacionais, de novembro de 2018. Assim, evidencia-se mais um exercício de resistência, desta vez sem negar a nova Lei, mas no seu marco normativo para criar alternativas que garantam uma formação integral aos estudantes das escolas públicas.

Posição semelhante é verificada na análise dos documentos. Dos 14 materiais coletados entre atas de reuniões, pareceres e resoluções -, oito indicam uma posição de neutralidade no campo, principalmente em função de serem meramente descritivos. Outros cinco foram classificados como resistência, além de um sexto que ficou dividido entre resistência e alinhamento. Da mesma forma que ocorreu em relação às notícias, desde a mudança na composição do Conselho, em abril de 2018, até o encerramento desta pesquisa, em dezembro de 2018, o número de materiais foi limitado. Isso se deve, principalmente, ao fato de não ter ocorrido nenhuma reunião do Grupo de Trabalho criado para discutir a reforma do Ensino Médio, o que dificulta a compreensão da posição do órgão a partir desse momento.

O primeiro documento incluído na categoria de resistência trata da ata da sessão plenária do dia 28 de setembro de 2016, logo após a apresentação da MP No 743/2016. Dois conselheiros fizeram manifestações incisivas de contrariedade às mudanças. Jaqueline Moll disse que "nem os militares mudaram o Ensino Médio por Medida Provisória""14. Já Antonio Quevedo Branco afirmou que a reforma "dificulta cada vez mais a escola de fazer o seu papel"15. Chama atenção que as duas manifestações foram feitas por conselheiros indicados pelo governo Tarso e que deixaram o CEED em abril de 2018. Não houve, durante a sessão, nenhuma manifestação favorável à reforma e, no encerramento, ficou definida a escrita de uma manifestação pública pela retirada da MP $\mathrm{N}^{\circ} 746$, conforme detalhamos na análise das notícias.

\footnotetext{
${ }^{14}$ As atas das reuniões do CEED foram disponibilizadas à pesquisa. A íntegra desses documentos pode ser conferida em: <https://lume.ufrgs.br/handle/10183/194560>. Acesso em: 7 set. 2019.

15 Conferir documento em: <https://lume.ufrgs.br/handle/10183/194560>. Acesso em: 7 set. 2019.
}

Práxis Educativa, Ponta Grossa, v. 15, e2014653, p. 1-21, 2020 
Um segundo documento relevante para a análise compreende a súmula da primeira reunião do Grupo de Trabalho sobre a reforma do Ensino Médio, realizada no dia 28 de novembro de 2017. Entre diferentes manifestações com preocupação sobre a Lei $N^{0} 13.415 / 2017$ e com a atuação do Conselho frente às mudanças, está a da conselheira Carmen Craidy, representante da Associação das Escolas Superiores para a Formação Docente (AESUFOPE). O posicionamento dela pode ser considerado uma síntese da categoria de resistência em relação à reforma, visto que, em um primeiro momento, aponta para uma rejeição às mudanças, mas, em seguida, manifesta o entendimento de que, já que havia se tornado lei, era imprescindível fazer as regulamentações necessárias para evitar mais prejuízos à formação dos jovens. O que disse a conselheira:

\begin{abstract}
A maneira como se deu a reforma foi arbitrária, por meio de uma medida provisória do governo federal, seguida por uma lei já com modificações. A BNCC já tem inúmeros pontos questionados. O GT pode realizar uma reflexão para construir essa reforma. A lei já está em vigor e será aplicada. É função do CEED fiscalizar e normatizar esse processo de mudança. (CEED, 2017 apud CHAGAS, 2019, p. 116, grifo nosso).
\end{abstract}

O entendimento de Carmen Craidy é mantido quando das discussões sobre as Diretrizes Operacionais para o Ensino Médio. $\mathrm{Na} A$ ta $\mathrm{N}^{\circ}$ 2.802, da sessão plenária do CEED, do dia 21 de março de 2018, em que o documento foi aprovado por unanimidade (Resolução No 340, de 2018), a conselheira diz que as diretrizes podem "instrumentalizar o Sistema e as escolas para a própria interpretação da BNCC, dando a ela uma dimensão pedagógica mais ampla" (CHAGAS, 2019, p. 117). Nesse sentido, vale retomar Bourdieu (2004) quando ele afirma as tomadas de posição dentro do campo estão relacionadas ao lugar que os agentes ocupam, aos capitais de que dispõem e ao seu habitus, em outras palavras, às disposições adquiridas pelos agentes que podem levá-los a resistir dentro do campo.

Também é fundamental para a análise dentro da categoria de resistência a íntegra das Diretrizes Curriculares aprovadas na sessão mencionada anteriormente. Não se trata de um documento que rejeita a reforma do Ensino Médio, mas abre novas possibilidades de atuação, uma resistência no sentido de transformar a posição dominante no campo. O Artigo $4^{\circ}$ das novas diretrizes, por exemplo, mostra a posição do CEED em relação à função do Ensino Médio e à necessidade de rompimento com o modelo dual, característico da constituição histórica da etapa uma concepção diferente daquela presente nas novas DCNEM, homologadas em 2018 pelo MEC.

\footnotetext{
Art. $4^{\circ} \mathrm{O}$ Ensino Médio é a etapa conclusiva da Educação Básica, e deverá aprofundar e consolidar conhecimentos, atitudes, valores e habilidades que permitam aos estudantes a tomada de decisões e posicionamentos em sociedade, superando o caráter dual de mera passagem para os estudos superiores ou para o mercado de trabalho. (CEED, 2018b, p. 2).
}

Outro ponto importante do documento é em relação à progressiva oferta da etapa nas proximidades da residência do estudante e de políticas de transporte escolar. Isso vai resultar em debates futuros quando da implementação da Lei $N^{\circ}$ 13.415/2017 nas escolas, já que $72 \%$ dos municípios gaúchos (CHAGAS; SARAIVA, 2018) contam com apenas uma instituição de Ensino Médio. Caso o estudante queira cursar um itinerário diferente dos que serão ofertados na escola de sua cidade, haverá transporte para que se desloque a outra cidade? Haverá planejamento microrregional para a oferta de variedade de itinerários formativos? Se a preocupação for com a liberdade de escolha do estudante e a qualidade da oferta, a resposta seria sim. Cabe sabermos, portanto, das condições de planejamento e financeiras para isso se efetivar, o que será motivo de novos estudos.

Sobre a organização curricular, o texto diz que será composta de “[...] uma base comum e uma parte diversificada que não devem constituir blocos distintos, mas um todo integrado" (CEED, 2018b, p. 4). Sobre a parte diversificada, indica que deve ser composta "[...] de uma 
formação que considere a diversidade e as características locais e especificidades regionais, e aspectos específicos das culturas juvenis, adultas e idosas" (CEED, 2018b, p. 4. Esses trechos reforçam a estratégia de incorporar a Lei $\mathrm{N}^{\circ}$ 13.415/2017 e dar-lhe forma para cumprir o compromisso com uma formação integral dos estudantes.

Um último documento analisado no escopo desta pesquisa, e que vale ser destacado neste artigo, compreende à Ata $\mathrm{N}^{\circ}$ 2.842, da Sessão Plenária de 18 de dezembro de 2018, a primeira realizada no CEED após a homologação da BNCC do Ensino Médio pelo MEC. O material foi enquadrado tanto como resistência tanto como alinhamento, já que aparece uma divisão de posições contrárias e favoráveis à reforma. É um documento de grande importância para a análise porque indica algumas posições do CEED após a mudança de sua composição, já que, desde a posse dos novos membros, em abril de 2018, não houvera nenhum movimento significativo do órgão em relação à Lei $\mathrm{N}^{\circ} 13.415 / 2017$. Os debates centraram-se em torno da preocupação com a oferta de parte das atividades na modalidade a distância e na defesa dos encaminhamentos feitos pelo Governo do Estado para a implementação do novo modelo, como a criação de escolas-piloto. A preocupação era ora de temor pelo que viria à frente, ora de alinhamento à proposta federal, em uma tentativa de tranquilizar sobre as ações em andamento.

A análise dos documentos e das notícias aponta que houve, em um primeiro momento, uma clara e geral posição de resistência à reforma do Ensino Médio no CEED, como fica evidente na manifestação pública do órgão pela retirada da MP No 746/2016. Como essa estratégia não teve efeito - a tramitação da MP avançou no Congresso Nacional, resultando na aprovação da Lei $\mathrm{N}^{\circ}$ 13.415/2017 - houve uma mudança para outra estratégia: de resistência dentro da norma: de trabalhar em regulamentações da Lei que minimizem os efeitos negativos das mudanças para os jovens das escolas públicas, como pode ser percebido no texto das diretrizes aprovadas em março de 2018.

Observa-se, nesse movimento, a força de articulação, dentro do campo educacional, da Comissão de Ensino Médio e Educação Superior, presidida pela professora Jaqueline Moll até abril de 2018, que liderou o processo de construção das Diretrizes, aprovadas por unanimidade no Conselho. Com o término do mandato dela e de outros, houve o ingresso de conselheiros nomeados pelo governador Sartori, ficando mais difícil observar essa resistência, principalmente porque não houve nenhuma manifestação oficial do Conselho em relação a Lei No 13.415/2017 de abril até dezembro de 2018. Novos estudos serão feitos no sentido de monitorar a atuação do CEED, já que ainda passarão pela análise do colegiado do órgão o referencial curricular do Ensino Médio e a proposta de flexibilização curricular para as escolas do Estado.

\section{Alinhamentos e resistências}

Os resultados da análise documental mostram que existe um alinhamento entre as propostas do Ministério da Educação para o Ensino Médio e as ações da Seduc-RS, agente que assumiu uma função de simples reprodução das orientações federais - fortemente ligadas ao projeto de educação hegemônico no campo econômico - sem preocupação com uma construção democrática, envolvendo estudantes, professores e comunidade escolar. Por outro lado, constatase do outro agente analisado neste estudo uma posição diferente. O CEED desempenhou uma função de resistência às mudanças na etapa, com a defesa de um projeto de educação que valorize a formação integral dos alunos. No entanto, seus últimos movimentos em 2018 não confirmam a manutenção de atitude de resistência, pois havia convicção sobre a legitimidade da participação das comunidades escolares nas decisões de política educacional. 
Foi interessante observar que a Seduc teve a sua estrutura alterada no começo de 2018, com a indicação de finalidades que deixam muito clara a sua posição dentro do campo em relação à reforma do Ensino Médio. No Decreto $\mathrm{N}^{\circ}$ 54.015/2018, não há nenhuma menção, entre as atribuições da Seduc, de planejamento de políticas para a Educação Básica; são apenas de execução, promoção, financiamento e fiscalização de políticas. Esse ponto do documento sintetiza toda a análise que fizemos das notícias e dos documentos produzidos em relação às mudanças, os quais tivemos acesso para esta pesquisa. A Seduc constou como executora de decisões exógenas, deixando de lado as funções de planejamento e de gestão de políticas para a Educação Básica, em especial para o Ensino Médio, como preconizam os Planos Nacional e Estadual de Educação, de acordo com o ordenamento federativo do Brasil.

Tanto as notícias oficiais quantos os documentos produzidos pela Seduc-RS evidenciam alinhamento às orientações da União, já que nenhum deles apresenta uma visão crítica ou problematiza pontos da reforma. Percebemos nos materiais a reprodução integral dos argumentos do MEC para justificar a mudança e, ainda, aderência ao cronograma de implementação definido com o Consed e as fundações empresariais - responsáveis por criar, gerir e financiar um curso para técnicos das secretarias estaduais ministrado no Insper, em São Paulo, e um grupo de trabalho do "novo" Ensino Médio. Fica clara a força dos agentes do campo econômico na construção de uma agenda de implementação da reforma dentro da Seduc-RS, além da ausência de debate com as comunidades escolares. A promessa de diálogo do então Secretário Luís Antônio Alcoba de Freitas tornou-se um discurso retórico, que não se traduziu em ações concretas por uma construção democrática.

Identificamos, ainda, que existe preocupação sobre como será a oferta dos itinerários formativos nos municípios que contam com apenas uma escola de Ensino Médio. Isso está presente nas apresentações com diagnóstico da situação da etapa feitas pela Secretaria. No entanto, os documentos e as notícias não apontam nenhum indicativo de como resolver esse entrave. Também não verificamos propostas relacionadas à melhoria das condições de infraestrutura das escolas estaduais, nem um detalhamento sobre como ampliar a Educação Profissional e sobre como garantir a atuação de professores com formação adequada.

Conforme a análise da Lei $\mathrm{N}^{0} 13.415 / 2017$, o único caminho apresentado para os problemas estruturais e de recursos humanos das escolas é a oferta do ensino a distância, por meio de parcerias privadas, o que deve reforçar as desigualdades educacionais. Soma-se a isso o contexto de corte de investimentos a partir da Emenda Constitucional $N^{\circ} 95$, que definiu um teto para os gastos públicos por 20 anos e que afeta diretamente as políticas educacionais. No Rio Grande do Sul, a situação é ainda mais grave tendo em vista a crise financeira do Estado, com profissionais da educação sem receber em dia seus salários e escolas com problemas de infraestrutura (CHAGAS; SARAIVA, 2018).

Concordamos com Kuenzer (2000) em que, não sendo considerados os problemas estruturais e conjunturais que envolvem a oferta do Ensino Médio, corre-se o risco de reconhecer as propostas de reforma como eivadas de ingenuidade ou de má-fé. Entendemos que o projeto de educação proposto pelo MEC, seguido à risca pela Seduc-RS, representa uma inflexão nas políticas que buscavam romper com a dualidade histórica da educação brasileira. Ao não requerer e promover condições mais equitativas de infraestrutura e de formação docente, além de legitimar a oferta dos itinerários formativos de acordo com as condições atuais das escolas, temos a precarização do Ensino Médio público legitimada pela norma.

Assim como na Seduc, no Conselho também houve mudanças na composição durante o período em análise. Até abril de 2018, verificou-se uma clara resistência à reforma do Ensino Médio. Em um primeiro momento, houve rejeição às alterações, inclusive com pedido do CEED 
de retirada da MP $N^{\circ}$ 746/2016. Depois, quando se tornou Lei, o movimento de resistência deuse em torno de pareceres e das novas Diretrizes Curriculares para o Sistema Estadual, que não negam a norma empreendida pelo Governo Federal, mas buscam compatibilizar as novas determinações à concepção de formação integral dos jovens e romper com o dualismo histórico, que separou a educação brasileira em uma escola para os ricos e outra para a maioria popular. Essa dinâmica do CEED pode ser compreendida pelo que Bourdieu (2011) define como o jogo desenvolvido pelos agentes dentro do campo, que utilizam o babitus para desenvolver estratégias de resistência. Se as disposições adquiridas indicam que negar a norma já não é mais eficaz, a resistência se dá dentro da norma.

Após a posse dos novos conselheiros, até a conclusão da coleta de documentos para esta pesquisa, em dezembro de 2018, não houve nenhuma manifestação do órgão sobre o tema, o que dificulta a compreensão se a nova composição do órgão se reflete em mudança na característica de resistência. Permanece, assim, um ponto de interrogação sobre a atuação do agente, sendo necessários novos estudos, já que o órgão terá de se manifestar sobre a regulamentação da BNCC e sobre a implementação dos itinerários formativos nas escolas.

Como afirmam Ball, Maguire e Braun (2016, p. 15), a política não é imposta às escolas sem contestação, ela "[...] é analisada e revista, bem como, por vezes, dispensada e esquecida". Os próximos anos serão decisivos para o futuro do Ensino Médio, tendo em vista que os documentos coletados junto à Seduc indicam a realização de um projeto-piloto do "novo" Ensino Médio em escolas da Rede Estadual do Rio Grande do Sul, com a adoção dos itinerários formativos dentro da proposta de flexibilidade curricular a partir de 2020. Como o escopo de análise apontou que não houve, de parte da Seduc, questionamentos, resistência ou um planejamento de ações diferente do que foi pautado de forma autoritária pelo MEC, passaremos a acompanhar como educadores, gestores, estudantes e comunidade escolar interpretarão e traduzirão as normas em sintonia com as suas realidades e interesses.

\section{Referências}

BALL, S. J.; MAGUIRE, M.; BRAUN, A. Como as escolas fazem as políticas: atuação em escolas secundária. Tradução Janete Bridon. Ponta Grossa: Editora UEPG, 2016.

BOURDIEU, P. Os usos sociais da ciência: por uma sociologia clínica do campo científico. São Paulo: Editora UNESP, 2004.

BOURDIEU, P. O campo político. Revista Brasileira de Ciência Política, Brasília, n. 5, p. 193216, jan./jul. 2011. DOI: http://dx.doi.org/10.1590/S0103-33522011000100008

BRASIL. Lei $\mathrm{N}^{\mathrm{o}}$ 13.415, de 16 de fevereiro de 2017. Altera as Leis $\mathrm{N}^{\text {os }}$ 9.394, de 20 de dezembro de 1996, que estabelece as diretrizes e bases da educação nacional, e 11.494, de 20 de junho 2007, que regulamenta o Fundo de Manutenção e Desenvolvimento da Educação Básica e de Valorização dos Profissionais da Educação, a Consolidação das Leis do Trabalho - CLT, aprovada pelo Decreto-Lei no 5.452, de 1o de maio de 1943, e o Decreto-Lei no 236, de 28 de fevereiro de 1967; revoga a Lei no 11.161, de 5 de agosto de 2005; e institui a Política de Fomento à Implementação de Escolas de Ensino Médio em Tempo Integral. Diário Oficial da União: seção 1, Brasília, DF, n. 35, p. 1-3, 17 fev. 2017. 
BRASIL. Portaria $n^{\circ} 1.145$, de 10 de outubro de 2016. Institui o Programa de Fomento à Implementação de Escolas em Tempo Integral, criada pela Medida Provisória $n^{\circ} 746$, de 22 de setembro de 2016. Diário Oficial da União: seção 1, Brasília, DF, p. 23-25, 11 out. 2016.

BRASIL. Portaria No 649, de 10 de julho de 2018. Institui o Programa de Apoio ao Novo Ensino Médio e estabelece diretrizes, parâmetros e critérios para participação. Diário Oficial da União: seção 1, Brasília, DF, n. 132, p. 72, 11 jul. 2017.

CEED. Conselho Estadual de Educação (Rio Grande do Sul). Manifestação CEED. 2016. Disponível em: <http://www.ceed.rs.gov.br/conteudo/13144>. Acesso em: 10 jan. 2019.

CEED. Conselho Estadual de Educação (Rio Grande do Sul). Orientações sobre implementação do novo ensino médio - lei 13.415/2017. 2017a. Disponível em: <http://www.ceed.rs.gov.br/conteudo/13758>. Acesso em: 7 set. 2019.

CEED. Conselho Estadual de Educação (Rio Grande do Sul). Parecer CEED no 02/2017. Orienta o Sistema Estadual de Ensino quanto à aplicação da Lei federal $n^{\circ}$ 13.415. 2017b. Disponível em: < http://www.ceed.rs.gov.br/upload/1494612109_Parecer_002.pdf >. Acesso em: 20 ago. 2019.

CEED. Conselho Estadual de Educação (Rio Grande do Sul). Conselho aprova Diretrizes Curriculares Operacionais para o Ensino Médio. 2018a. Disponível em: <http://www.ceed.rs.gov.br/conteudo/21213/conselho-aprova-diretrizes-curricularesoperacionais-para-o-ensino-medio- $>$. Acesso em: 7 set. 2019.

CEED. Conselho Estadual de Educação (Rio Grande do Sul). Resolução CEED n⿳ 340, de 21 de março de 2018. Define as Diretrizes Curriculares para a oferta do Ensino Médio no Sistema Estadual de Ensino. 2018b. Disponível em: <http://www.ceed.rs.gov.br/download/20180327150103resolucao_0340.pdf>. Acesso em: 20 ago. 2019.

CHAGAS, A. B. Os primeiros passos para a implementação da reforma do Ensino Médio na rede estadual do RS: projetos em disputa. 2019. 292 f. Dissertação (Mestrado em Educação) - Universidade Federal do Rio Grande do Sul, Porto Alegre, 2019.

CHAGAS, A.; SARAIVA, M. A reforma do Ensino Médio e os entraves ao direito à educação nas escolas públicas do Rio Grande do Sul. In: REUNIÃO CIENTÍfFICA DA REGIONAL DA ANPED, 12., 2018, Porto Alegre. Anais eletrônicos [...]. Porto Alegre: UFRGS, 2018. Disponível em: $\quad<$ http://anais.anped.org.br/regionais/sites/default/files/trabalhos/2/1955TEXTO_PROPOSTA_COMPLETO.pdf>. Acesso em: 20 dez. 2019.

FERRETTI, C. J. A reforma do Ensino Médio e a sua questionável concepção de qualidade da educação. Estudos Avançados, São Paulo, v. 32, n. 93, p. 25-42. 2018. DOI: http://dx.doi.org/10.5935/0103-4014.20180028

FERRETTI, C. J.; SILVA, M. R. Reforma do Ensino Médio no contexto da Medida Provisória no 746/2016: Estado, currículo e disputas por hegemonia. Educação \& Sociedade, Campinas, v. 38, n. 139, p. 385-404, abr./jun. 2017. DOI: http://dx.doi.org/10.1590/es0101-73302017176607 
INEP. Instituto Nacional de Estudos e Pesquisas Educacionais Anísio Teixeira. Sinopse Estatística da Educação Básica 2018. Brasília: Inep, 2019. Disponível em: <http://inep.gov.br/sinopses-estatisticas-da-educacao-basica>. Acesso em: 27 set. 2019.

KUENZER, A. Z. O Ensino Médio agora é para a vida: entre o pretendido, o dito e o feito. Educação \& Sociedade, Campinas, v. 21, n. 70, p.15-39, abril. 2000. DOI: http://dx.doi.org/10.1590/S0101-73302000000100003

KUENZER, A. Z. Trabalho e Escola: a flexibilização do Ensino Médio no contexto do regime de acumulação flexível. Educação \& Sociedade, Campinas, v. 38, n. 138, p. 331-354, abr./jun. 2017. DOI: http://dx.doi.org/10.1590/es0101-73302017177723

PERONI, V. et al. Reformas educacionais de hoje: as implicações para a democracia. Revista Retratos da Escola, Brasília, v. 11, n. 21, p. 415-432, jul./dez. 2017. DOI: http://dx.doi.org/10.22420/rde.v11i21.793

RIO GRANDE DO SUL (Estado). Decreto No 51.906, de 14 de outubro de 2014. Dispõe sobre a estrutura básica da Secretaria da Educação. Porto Alegre: Assembleia Legislativa, Gabinete de Consultoria Legislativa, [2014]. Disponível em: $<$ http://www.al.rs.gov.br/filerepository/repLegis/arquivos/DEC\%2051.906.pdf >. Acesso em: 20 dez. 2019.

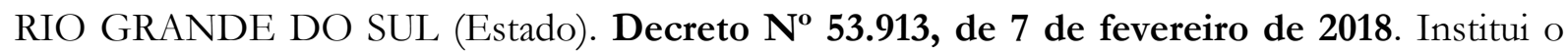
Programa de Educação em Tempo Integral no Ensino Médio, nas escolas da rede estadual. Porto Alegre: Assembleia Legislativa, Gabinete de Consultoria Legislativa, [2018a]. Disponível em: $<$ http://www.al.rs.gov.br/filerepository/repLegis/arquivos/DEC\%2053.913.pdf>. Acesso em: 20 dez. 2019.

RIO GRANDE DO SUL (Estado). Decreto $\mathbf{N}^{\mathbf{0}} \mathbf{5 4 . 0 1 5}$, de 10 de abril de 2018. Dispõe sobre a estrutura básica da Secretaria da Educação. Porto Alegre: Assembleia Legislativa, Gabinete de Consultoria Legislativa, [2018b]. Disponível em: <http://www.al.rs.gov.br/filerepository/repLegis/arquivos/DEC\%2054.015.pdf>. Acesso em: 20 dez. 2019.

RIO GRANDE DO SUL (Estado). Governo entrega proposta a estudantes de escolas ocupadas. 2016a. Disponível em: <https://estado.rs.gov.br/governo-entrega-proposta-aestudantes-de-escolas-ocupadas >. Acesso em: 2 set. 2019.

RIO GRANDE DO SUL (Estado). Lei No 14.705, de 25 de junho de 2015. Institui o Plano Estadual de Educação - PEE -, em cumprimento ao Plano Nacional de Educação - PNE -, aprovado pela Lei Federal n. ${ }^{\circ}$ 13.005, de 25 de junho de 20. Porto Alegre: Assembleia Legislativa, Gabinete de Consultoria Legislativa, [2015]. Disponível em: <http://www.al.rs.gov.br/filerepository/repLegis/arquivos/LEI\%2014.705.pdf>. Acesso em: 20 dez. 2019.

SEDUC. Secretaria da Educação (Rio Grande do Sul). Luís Alcoba faz balanço da gestão. 2017a. Disponível em: <https://educacao.rs.gov.br/luis-alcoba-faz-balanco-da-gestao $>$. Acesso em: 2 de set. 2019. 
SEDUC. Secretaria da Educação (Rio Grande do Sul). Ronald Krummenauer toma posse como secretário da Educação. 2017b. Disponível em: <https://educacao.rs.gov.br/ronaldkrummenauer-toma-posse-como-secretario-estadual-da-educacao $>$. Acesso em: 2 set. 2019.

SEDUC. Secretaria da Educação (Rio Grande do Sul). Sancionada, em Brasília, a lei do Novo Ensino Médio. 2017c. Disponível em: <https://educacao.rs.gov.br/sancionada-a-medidaprovisoria-que-estabelece-o-novo-ensino-medio >. Acesso em: 2 set. 2019.

SEDUC. Secretaria da Educação (Rio Grande do Sul). Secretaria da Educação realiza reunião do Fórum Farol do Futuro. 2017d. Disponível em: < https://educacao.rs.gov.br/secretaria-daeducacao-realiza-reuniao-do-forum-farol-do-futuro >. Acesso em: 20 ago. 2019.

SEDUC. Secretaria da Educação (Rio Grande do Sul). Sexta-feira é dia de torcer pelo Brasil e debater a educação. 2018. Disponível em: <https://educacao.rs.gov.br/sexta-feira-e-dia-detorcer-pelo-brasil-e-debater-a-educacao >. Acesso em: 3 set. 2019.

SILVA, M. R. O golpe no ensino médio em três atos que se completam. In: AZEVEDO, J. C.; REIS, J. T. Políticas Educacionais no Brasil Pós-Golpe. Porto Alegre: Editora Universitária Metodista IPA, 2018. p. 41-54.

VERGER, A. A política educacional global: conceitos e marcos teóricos chave. Práxis Educativa, Ponta Grossa, v. 14, n. 1, p. 9-33, jan./abr. $2019 . \quad$ DOI: https://doi.org/10.5212/PraxEduc.v.14n1.001

Recebido em 01/09/2019

Versão corrigida recebida em 18/12/2019

Aceito em 19/12/2019

Publicado online em 27/12/2019 